\title{
Exploring the benefits and challenges of health professionals' participation in online health communities: Emergence of (dis)empowerment processes and outcomes
}

\author{
Original paper
}

\author{
Sara Atanasova $\mathrm{a}^{\text {* }}$ Tanja Kamin $^{\mathrm{b}}$ and Gregor Petrič ${ }^{\mathrm{a}}$ \\ ${ }^{\text {a } U n i v e r s i t y ~ o f ~ L j u b l j a n a, ~ F a c u l t y ~ o f ~ S o c i a l ~ S c i e n c e s, ~ C e n t r e ~ f o r ~ M e t h o d o l o g y ~ a n d ~}$ \\ Informatics, Kardeljeva pl. 5, 1000 Ljubljana, Slovenia \\ ${ }^{b}$ University of Ljubljana, Faculty of Social Sciences, Centre for Social Psychology, \\ Kardeljeva pl. 5, 1000 Ljubljana, Slovenia \\ *Corresponding author: sara.atanasova@fdv.uni-lj.si
}

How to cite: Sara Atanasova, Tanja Kamin, Gregor Petrič, Exploring the benefits and challenges of health professionals' participation in online health communities: Emergence of (dis)empowerment processes and outcomes, International Journal of Medical Informatics, Volume 98, February 2017, Pages 13-21, ISSN 1386-5056, https://doi.org/10.1016/j.ijmedinf.2016.11.005.

(http://www.sciencedirect.com/science/article/pii/S1386505616302544)

Keywords: Online health community; Health professionals; Moderators; Empowerment; Thematic analysis

(C) $<2017>$. This manuscript version is made available under the CC-BY-NC-ND 4.0 license http://creativecommons.org/licenses/by-nc-nd/4.0/

This is a post-print version of the article, the definitive version was published in International Journal of Medical Informatics. 2017. Volume 98, February 2017, Pages 13-21. The publisher's version of this article is available at https://doi.org/10.1016/j.ijmedinf.2016.11.005. 
Exploring the benefits and challenges of health professionals' participation in online health communities: Emergence of (dis)empowerment processes and outcomes

\begin{abstract}
Background: Various online applications and service has led to the development of online health communities (OHCs), which in addition to the peer-to-peer communication offer patients and other users also interaction with health professionals. While the benefits and challenges of patients and other users' participation in OHCs have been extensively studied, a thorough examination of how health professionals as moderators (i.e., those who provide clinical expertise to patients and other users in OHCs) experience participation in OHCs is lacking.
\end{abstract}

Objective: The aim of this study is to explore the main benefits and challenges of health professional moderators' participation in the OHCs.

Methods: The study undertakes an exploratory qualitative study, with in-depth semi-structured interviews with health professional moderators $(n=7)$ participating in the largest $\mathrm{OHC}$ in Slovenia, Med.Over.Net. The data was analysed using inductive thematic analysis approach and principles of grounded theory.

Results: Four themes of health professional moderators' experiences were identified: (a) benefits of addressing $\mathrm{OHC}$ users' health-related needs, (b) challenges of addressing $\mathrm{OHC}$ users' health-related needs, (c) health professional moderators' benefits, and (d) health professional moderators' challenges.

Conclusions: This small study demonstrates that health professional participating in OHCs as moderators perceive themselves as facilitators of patients and other $\mathrm{OHC}$ 's users empowering processes and outcomes, in which OHC's users improve their health literacy, develop skills, expand their social support, and gain other important resources necessary when dealing with health-related issues. Health professional moderator's role, however, also involves several 
duties, responsibilities and limitations that are often experienced as difficulties in providing patients and other users with adequate counselling and online medical service. OHCs also represent an important terrain for personal and professional empowerment of health professional moderators, although the presence of disempowering processes also needs to be noted.

Keywords: online health community; health professionals; moderators; empowerment; thematic analysis

\section{Introduction}

The widespread use of online health communities (OHCs) plays an important role in the transformation of the experiences of health care and chronic condition management among Internet users, patients, caregivers, health professionals, and policy makers alike (Hwang et al., 2010; Johnston, Worrell, Di Gangi, \& Wasko, 2013). OHCs, such as PatientsLikeMe, WebMD, and MedHelp present an Internet-based platforms that not only encompass participation from (potential) patients and/or caregivers, but they also include health professional moderators (Huh et al., 2016; Johnston et al., 2013; Petrovčič \& Petrič 2014a; Zhao, Ha, \& Widdows, 2013), and as such differ from online health support groups, that typically include patients only. Health professional moderators that participate in OHCs are usually health professionals (health care providers or doctors) who deliver health consultations and moderate health-related discussion and thus provide patients and other OHCs' users with reliable health-related information and clinical expertise.

Various studies have demonstrated that participation in OHCs provides patients and other users with several positive psychological benefits, like higher self-esteem, self-efficacy, and control related to managing their own health issues or health issues of the ones they care for, enhanced satisfaction from helping others, improved confidence in the relationship with doctors in formal ('offline') medical encounters, more competent use of health services, and even improved 
social well-being and quality of life (Mo \& Coulson 2012; Petrovčič \& Petrič, 2014a; van UdenKraan, Drossaert, Taal, Sevdel, \& van de Laar, 2009).

Ordinary users' experiences, benefits, and challenges associated with participation in OHCs have received a lot of research attention (e.g., Mo \& Coulson, 2010; van Uden-Kraan, Drossaert, Taal, Sevdel, \& van de Laar, 2008; Wentzer \& Bygholm, 2013), but almost no research is focused on question of what are the experiences of health professional moderators in OHCs. Health professional moderators in OHCs provide counselling, clarifications, explanations, as well as possible solutions, resources, and opinions about medical issues, remedies, and therapies for patients and other users (Huh, McDonald, Hartzler, \& Pratt, 2013). As such, they can substantially reduce the potentially problematic effects of $\mathrm{OHC}$ for users (Huh, 2015; Huh \& Pratt, 2014). For example, health professional moderators can help users to distinguish between valuable and misleading medical information, provide them with clinical expertise, facilitate group interactions, help to integrate new or less involved members, and encourage users who only read messages (i.e. lurkers) to start actively participating in the OHC (Huh et al., 2013; Huh \& Pratt, 2014). In addition, they might contribute to the success and sustainability of OHCs (Young, 2013).

Despite the acknowledgement that health professional moderators can improve the quality of OHCs, only a limited number of studies have been concerned with their role in OHCs (e.g. Huh, 2015; Huh et al., 2013; Huh et al., 2016; Huh \& Pratt, 2014; Jones \& Ashurst, 2013), but none of these empirically investigated health professional moderators' actual experiences of participation in OHCs. There have been a few studies that focused on moderators' perspectives (e.g., Coulson \& Shaw, 2013; Johnston et al., 2013; van Uden-Kraan, Drossaert, Taal, Sevdel, \& van de Laar, 2010), but the investigated moderators in these studies were former patients, patients living with chronic illnesses, and/or the initiators of OHCs rather than health professionals. Nevertheless, these studies do present relevant findings. They demonstrated that moderators may provide a unique insight into the $\mathrm{OHC}$ phenomenon, as they can offer medically related advice, and prevent health risks among patients (van 
Uden-Kraan et al., 2010). They also reveal that, users, who take on a moderation role in OHCs experience a positive impact on their personal and health-related life areas: improved illness management, better relationships with their doctors, and a higher level of confidence in accessing health services (Coulson \& Shaw, 2013).

Our research focuses only on moderators in OHCs that are health professionals and studies how they perceive and experience their participation in $\mathrm{OHC}$. We designed a small qualitative study to explore the participation of health professional moderators in Med.Over.Net, the largest $\mathrm{OHC}$ in Slovenia, in order to identify the main benefits and challenges of the engagement of health professionals as moderators in the OHC. With semi-structured interviews conducted with health professional moderators $(n=7)$ of Med.Over.Net community and data analysed using inductive thematic analysis approach and principles of grounded theory we sought answers to the following questions: What benefits and/or challenges do health professionals experience when participating as moderators in the OHC? What benefits and/or challenges do they see for themselves, $\mathrm{OHC}$ users and for the $\mathrm{OHC}$ as a whole?

\section{Materials and methods}

\subsection{Recruitment process and sampling}

Health professional moderators were recruited from Med.Over.Net, the largest $\mathrm{OHC}$ in Slovenia ${ }^{1}$, which was established in 2000 with focus on health, medicine, social work, and education related topics. This particular $\mathrm{OHC}$ was selected as it is one of the most visited online communities in Slovenia. It has more than 400,000 monthly visits and on average more than 70,000 monthly users, and it has already been the subject of studies on OHCs (Petrovčič \& Petrič, 2014a, 2014b). Med.Over.Net is an open access stand-alone online community that offers a variety of online discussion forums, i.e. online support group forums and online

\footnotetext{
${ }^{1}$ Slovenia is a European Union country with approximately 2 million inhabitants and at least 1.1 million weekly Internet users in the 16-74 cohort. In fact, Slovenia is one of the most typical EU countries with respect to usage of information-communication technologies. According to many of Eurostat information society indicators, it takes close to the median position among all EU countries (Statistical Office of Slovenia, 2015).
} 
counselling forums. The counselling forums, which are the focus of this study, cover topics ranging from acute or chronic health conditions to medical specialties handling particular diseases and medical states (e.g., dermatology, gynecology, oncology, psychiatry, preventive medicine etc.). In counselling forums health professional moderators represent the primary source of clinical expertise and support for patients and other users. Med.Over.Net's counselling forums are moderated by 150 health professional moderators and are structured in a question and answer (Q\&A) format, where questions are posted by patients and other users and then answered by health professional moderators. The health professional moderators are health care experts (medical doctors and specialists), psychotherapists, psychologists, and medical staff, employed in public and private health institutions in Slovenia and independently from this participate as volunteers in the studied OHC.

Health professional moderators in the study were recruited with the help of an online expression of interest form. Recruitment of participants was conducted with the support of Med.Over.Net community managers. In the online form, we explained the purpose of the study and their rights as participants, as well as asking for their contact information. The choice of interviewees was limited to health professional moderators from the field of health care or medicine. The study undertook a mixed purposeful sampling approach composed of both convenience and snowball sampling, resulting in recruitment of seven health professional moderators who participated in the studied $\mathrm{OHC}$ and who were willing to participate in the interviews. We obtained informed consent from all participants.

The sample size is in line with Braun and Clarke's (2013) guidelines for thematic analysis, which categorize suggestions by the type of data collection and the size of the project. As this was a small scale project, we followed the guideline of including 6-10 participants in the interviews. Data saturation was indicated by the overall thematic data replications.

\subsection{Data collection}


The data were collected through in-depth, semi-structured, face-to-face interviews conducted with health professional moderators from Med.Over.Net. In the interviews, the participants were asked to share their views and experiences concerning the following topics: reasons for voluntary participation in the $\mathrm{OHC}$, start of their involvement as health professional moderators, opinions and views about the Med.Over.Net OHC in particular, benefits and challenges of participation in the $\mathrm{OHC}$, the role of health professional moderators, relationships and interactions with users of the $\mathrm{OHC}$, and the role of the $\mathrm{OHC}$ in the overall health care system.

Participants were offered an incentive in the form of a gift card in the amount of $20 €$ before participation in the interviews. All except one of the interviews were conducted one-on-one in person in a quiet and secure room at the authors' office, participants' workplaces, or their homes. One of the participants was hearing-impaired and as an interpreter was not available for the interview, we conducted the interview via email. All of the interviews, except for the one conducted by email, were audio recorded and transcribed verbatim. The interviews, each lasting on average 1 hour and 8 minutes (except for the one conducted via email), were conducted in January and February 2015. The personal characteristics of the participants were anonymized to guarantee confidentiality and pseudonyms are used to preserve anonymity. At all stages of the research process we followed the Code of ethics for researchers of University of Ljubljana (2014).

\subsection{Participants}

The average age of the participants was 55, with the youngest being 42 and the oldest 94 . Two of the participants were male and five were female. With the exception of one person, all of the participants were employed. Five of the participants held a postgraduate degree and two of them had completed an undergraduate education. The participants had been involved in the health professional moderator role at the Med.Over.Net OHC from 1 to 13 years, with an 
average involvement of 8.7 years. They became health professional moderators either by invitation from community owners and managers, via a mediator, usually a colleague who was already involved with Med.Over.Net, or they were the initiators. The main motives for becoming a health professional moderator were similar to those identified in previous studies (Coulson \& Shaw, 2013; van Uden-Kraan et al., 2010), for example altruism like the provision of access to health-related information, and intrinsic such as opportunity for knowledge exchange, and promotion of their professional field or themselves as experts. The participants were health professionals that moderated a broad range of health-related topics in the $\mathrm{OHC}$, including cardiology, general practice, public health education, medical genetics, psychotherapy, and psychology.

\subsection{Data analysis}

The interviews were analysed using inductive thematic analysis with the assistance of Nvivo v10.0 software, according to the guidelines established by Braun and Clarke (2006). In addition we followed the principles of grounded theory by Strauss and Corbin (1998). The analysis was conducted by a member of the research team (SA) who also conducted all the interviews.

The coding procedure aimed to identify the main benefits and challenges health professional moderators participating in the $\mathrm{OHC}$ experience for themselves, $\mathrm{OHC}$ users and for the $\mathrm{OHC}$ as a whole. Prior to the coding process, the entire set of interview transcripts was first systematically read several times. The analytic process was conducted as an inductive and iterative open coding analysis, starting with the identification of distinct concepts in the data related to individual research questions. In the first analytical step codes were ascribed to meaning units (group of words, sentences or statements that have some common meaning). We developed a definition for each code, and established clear distinctions between them. After generating initial codes, the analysis included different codes with shared commonalities into initial set of themes. This process is also known as axial-coding in grounded theory approach 
(Strauss \& Corbin, 1998). In this process coding scheme was continuously refined. The analysis continued with revision of initial themes, searching for coherent patterns, followed by the process of defining and naming of themes. Final set of themes was created (i.e. selective coding by Strauss \& Corbin, 1998), by selecting main themes and their sub-themes, and determining the meaning and relationships between them.

The interviews were coded in sequential order. However, if a new code emerged in an interview, all of the data set already coded was reviewed and examined again. In so doing, the analysis was an iterative process, in which the emerging codes were constantly challenged and further refined at each step of the process. The saturation of codes was achieved with five interviews. For the transparency of the coding process, the overall coding procedure, potential themes, observations, ideas, and patterns in the data were noted and documented in memos. The coding process, framework, and results were discussed and elaborated between the authors, and any disagreements and discrepancies were resolved with the purpose of preserving the reliability of the findings.

\section{Results}

Our coding procedure that was led by research questions of perceived benefits and challenges of $\mathrm{OHC}$ for health professional moderators resulted in identification of four themes and their sub-themes (see Table 1): (a) benefits of addressing OHC users' health-related needs, (b) challenges of addressing OHC users' health-related needs, (c) health professional moderators' benefits, and (d) health professional moderators' challenges.

Table 1. Identified themes and sub-themes of benefits and challenges of the $\mathrm{OHC}$ as perceived by health professional moderators.

\begin{tabular}{|l|l|}
\hline Themes & Sub-themes \\
\hline
\end{tabular}




\begin{tabular}{|l|l|}
\hline $\begin{array}{l}\text { Benefits of addressing } \\
\text { OHC users' health- } \\
\text { related needs }\end{array}$ & $\begin{array}{l}\text { Sharing health-related knowledge, raising awareness, granting } \\
\text { exchange of patient expertise and support, contributing to OHC } \\
\text { users' satisfaction, building cooperative professional- } \\
\text { patient/other OHC user relationship. }\end{array}$ \\
\hline $\begin{array}{l}\text { Challenges of } \\
\text { addressing OHC users' } \\
\text { health-related needs }\end{array}$ & $\begin{array}{l}\text { Providing ethics and data protection, dealing with a lack of key } \\
\text { information, adapting medical terminology, providing } \\
\text { information and emotional support simultaneously, problem } \\
\text { with inventiveness, professional conflicts. }\end{array}$ \\
\hline $\begin{array}{l}\text { Health professional } \\
\text { moderators' benefits }\end{array}$ & $\begin{array}{l}\text { On a personal level: self-fulfilment and self-worth, satisfaction, } \\
\text { sense of community. } \\
\text { On a professional level: additional education and research, } \\
\text { gaining recognition and respect. }\end{array}$ \\
\hline $\begin{array}{l}\text { Health professional } \\
\text { moderators' challenges }\end{array}$ & $\begin{array}{l}\text { On a personal level: feeling overloaded, overcommitted, } \\
\text { affected by tough cases. } \\
\text { On a professional level: feeling uncertain about co- } \\
\text { responsibility approach, feelings of public exposure. }\end{array}$ \\
\hline
\end{tabular}

\subsection{Benefits of addressing $\mathrm{OHC}$ users' health-related needs}

The health professional moderators described a series of experiences and practices in the counselling forums in which they create opportunities for the OHC's users to develop skills and receive social support and other resources necessary when dealing with health-related issues and conditions. With these experiences and practices, the health professional moderators believe that they can provide beneficial outcomes for the OHC's users and enable them to gain greater access to information and resources, thereby increasing their competences and feelings of control over their health condition or health condition of their close ones and its circumstances. We labelled these practices as the perceived benefits of addressing users' health-related needs. The health professional moderators described how, by participating in the OHC's counselling forums, they have opened up an opportunity to share and transfer health-related knowledge to users and thus contribute to a higher level of informed patients 
and other users: 'By participating in the forums, users can increase their knowledge, inform, and informally educate themselves' (Sofia, public health educator).

Further, the health professional moderators perceived the counselling forums as a great opportunity to raise awareness among wider group of people about particular health conditions, address misconceptions about illnesses and potentially influence de-stigmatization of rare health conditions:

....and I publicly wrote a couple of things on this subject, because you know, when people start to say or write that depressed people are actually only lazy people who don't have any other problems in their life and that they should only workout a little bit, such things can be harmful. (Blanca, psychiatrist)

The health professional moderators also highlighted granting an exchange of patient expertise and social support, which allows users to exchange their views and experiences about healthrelated information and health conditions, and even to comment on medical advice given by health professional moderators. As Jane (psychologist) emphasized: ‘...a valuable aspect of the forum is the fact that people can independently form personal contacts. Um, they come in contact, support each other, and create a social network that I think is very important.'

From this perspective, the health professional moderators also perceived the importance of user participation in the counselling forums for the activity and success of the $\mathrm{OHC}$, or as Sofia (public health educator) phrased it: 'OHC users are the forum's source of life.' They also reported that acting as health professional moderators they contributed to OHC users' satisfaction with the service provided by the counselling forums: '... users often express gratitude for being heard. I think being heard is the most important part of it. It is not so much about how well I prepared the answer, but about the feeling of being heard' (Jane, psychologist). 
The role of health professional moderator provides $\mathrm{OHC}$ participants with an opportunity to establish an improved partnership between health professionals and patients/other OHC users also in formal ('offline') medical encounters. The health professional moderators reported the possibility to work on building trust and confidence between users, giving them an opportunity to talk about their issues, encourage shared decision making, expand access to care, and build on mutuality between professionals and patients:

I think that we are more accessible, practically accessible, for anyone and I think that this can influence also the general relationship between doctors and patients and users' overall opinion about health care, it may even help in the long term. (Mark, general practitioner)

\subsection{Challenges of addressing OHC users' health-related needs}

The health professional moderators experienced several difficulties arising from interactions with $\mathrm{OHC}$ users. They exposed several factors that potentially decrease the level of possibilities to (efficiently) help and support users with their health-related issues. We labelled them as challenges of addressing OHC users' health-related needs, as they relate to health professional moderators' practices, which can have critical/problematic consequences for users in getting health-related information, resources, competences, and feelings of control over difficult health issues.

First, several health professional moderators mentioned ethical principles and data protection to be one of the most important challenging factors:

In my work, I need to guarantee the protection of personal data and the professionalism of my work. I understand that it is necessary to uphold ethics in communication with the users without insults, the abuse of personal data and so on. (Sofia, public health educator)

The health professional moderators were also aware that their medical advice can have an important effect on users' health-related decisions: 
We find ourselves in delicate situations, I don't mean delicate as in morally problematic, but delicate in the sense that we might find ourselves in situations where we lead someone to making poor decision, like when he or she decides on to medicate him- or herself at home... (Mark, general practitioner)

The health professional moderators emphasized the importance of developing distance in relationships with the OHC's users. As Robert (cardiologist) explained:

You need to be careful, approach everyone with a distance, because you never know if some has information already from his/her doctor, friend, or anyone else. Many times it's important to know how to answer, you always need to have your back protected.

Second, the health professional moderators discussed several difficulties arising from the lack of key information provided by $\mathrm{OHC}$ users that is often needed for more detailed diagnosis and correct health-related advice:

It happens many times that you don't have enough information. Genetics is a field of disease heritage, which means that you need to have information on how a specific illness appeared among family members, and such information is often missing... (Sabina, medical geneticist)

Some health professional moderators associated the lack of information with an inadequate general impression of the user, insufficient or even intentionally omitted important healthrelated information: '...the user decides by himself which problems seem to him important for you, and you don't have any possibility to explore and research in any other direction, and this can be problematic' (Mark, general practitioner).

Some health professional moderators were often confronted with the need to adapt medical terminology when explaining clinical terms, diagnoses, or specific indications of health conditions to $\mathrm{OHC}$ users. In some situations, the health professional moderators struggled with adapting the language to be more suitable for users' level of understanding. As Sabina (medical geneticist) explained: 
...I noticed that people wanted, needed simpler answers. But I must say, medicine is not that simple and maybe I didn't know how to simplify to an appropriate level, but people were still asking about the serious health problems of their relatives and this can't just be simplified, so this was quite demanding for me.

The fourth challenge that the health professional moderators mentioned was to provide users with informational and emotional support simultaneously. In addition to offering health-related advice, useful information and resources (which are primary tasks of health professional moderators), users often expected to receive empathy, reassurance, care, and understanding. However, the health professional moderators find it very challenging to address both types of support simultaneously:

...then [name of community manager] warned me that people maybe just need some compassionate contact and not so professional answers as mine were. But this is me, I can't um, if someone asks me a specific question I know how to answer that question, also in a more caring sense, but I can’t just use nice words. (Sabina, medical geneticist)

Furthermore, the health professional moderators discussed a dilemma we labelled the problem with inventiveness, which more specifically describes the health professional moderators' fear that due to answering a high amount of questions, they will repeat themselves in their replies to users. This feeling was more often identified by participants with longer moderator experience, who were confronted with many (similar) cases. Some health professional moderators felt that they were at risk of becoming less creative as moderators, which could eventually affect their quality of work and consequently users' satisfaction:

You feel like that the thirtieth user asked you the same issue as 29 users before, but he/she sees it as a unique problem ... and sometimes it's hard, but you see by the response of the person that although you used almost similar or even identical words, he/she feels personally addressed. I hope he/she doesn't feel like he/she received a copy paste response, although I don't do copy paste (laughter). In my mind maybe I do copy paste. (Jane, psychologist) 
Another perceived challenge is related to the professional conflicts that are implicitly present in the OHC. Health professional moderators noted a lack of collaboration with other health professional moderators with different fields of expertise, especially in cases when users' health-related problems are complex and could/should be assessed by more than one specialist. The health professional moderators believed that such lack of collaboration between different professionals already emerge from professional disagreements in the general health care system, which they felt to have been reproduced in the OHC. As Lucia (psychologist) explained:

...professionals think that when they receive a question from a user they can answer anything, that a gynaecologist can answer a question about prenatal psychological distress. I have a lower authority than gynaecologists, or so they think, because they are medical doctors. So a gynaecologist will never forward me a user's question, they will just write to them "it's nothing you should be worried about" ... This means that a woman should visit four, five specialists, and no one can cover all of her problems because each of them will give her their own directions.

\subsection{Health professional moderators' benefits}

The health professional moderators reported several benefits of participating in the $\mathrm{OHC}$ in terms of an increased ability to exert influence on their personal and professional life. Moreover, they reported experiencing an increased sense of meaning, impact, and competence on the personal and professional level. We labelled such beliefs as health professional moderators' benefits.

The health professional moderators noted that their moderating role brought them increased feelings of self-fulfilment and self-worth. Due to the possibility to help other people and 'give back to society,' they experienced an improved sense of their own value as a person, as well as increased self-respect, self-esteem, self-development, and self-realization: 
I gained confidence, confidence in my writing, in my public appearance, and of course in my practices, therapies. I see now that I am maybe more relaxed, a little bit more soft, and also social ... I feel fine about it. I feel good about it. I truly think that I'm doing something I couldn't say no to. It doesn't have a financial worth, but I gain so much from it. This is my contribution to society. (Jane, psychologist)

Feelings of self-fulfilment go hand in hand with the sense of satisfaction that often emerged from users' gratitude and positive feedback: 'For me, it is also a pleasure, many times I received such positive feedback, people thanked me and that meant everything to me...' (Sabina, medical geneticist). This satisfaction is also reflected in their appreciation for the opportunity to be involved in the $\mathrm{OHC}$ as health professional moderators: 'I would feel impoverished, if I wouldn't be able to do this anymore' (Robert, cardiologist).

Several health professional moderators also noted that through their participation in the $\mathrm{OHC}$ they have developed a feeling of belonging, a sense of connectedness with others in the $\mathrm{OHC}$, acceptance, and a sense of community:

I'm a family member there (laughter), it is a little bit different, but I'm a part of it and it is a part of me ... I need to say that I feel a part of a team ... I must say that it would be difficult for me to give up Med.Over.Net, I'm almost emotionally attached (laughter). (Blanca, psychiatrist)

Furthermore, they emphasized the advantages they gained on a professional level also in their ('offline') health care practice, namely additional education and research due to participating in the $\mathrm{OHC}$ :

... at the beginning, I really enjoyed researching, because everything was new to me, like a new world, and it gave me the opportunity to, how to say this, to develop my field of specialty. Users taught me so much from their experiences, I really advanced myself, so I became better at my profession. (Lucia, psychologist)

Their experience of moderating also encouraged them to stay up to date with all the novelties in the constantly developing field of medicine: 
So one benefit is certainly the fact that if you want to seriously answer users' questions, you need to constantly look at what was published last week in relation to the question's topic. In genetics, every day brings some novelty and so this is a kind of professional learning and advancement opportunity for moderators. (Sabina, medical geneticist)

Several participants reported increased feelings of professional recognition and respect: 'You can meet a lot of people, and I don't only mean the users, but also others who are present, you know someone who invites you to write an article, which means that in some way we gain recognition' (Mark, general practitioner). Such professional recognition also serves as confirmation of their professional credibility, which in their opinion contributes to building trust with the OHC's users:

Um, many people have a feeling that if something is on the Internet then it is more credible and if someone writes on the Internet then it means that he/she is serious about it. We can't afford to write just anything to someone publicly online, so if someone is as publicly exposed as we are, he/she must be trustworthy. (Blanca, psychiatrist)

Some of the health professional moderators saw the public exposure, professional recognition, and acknowledgment as an opportunity for the commercial marketing of their own private practices: 'Well, the benefit is the fact that when OHC users get an answer, and are satisfied, they also sometimes come to face to face therapy to the medical office or a clinic' (Jane, psychologist).

\subsection{Health professional moderators' challenges}

The health professional moderators also reported several disadvantages related to their participation in the $\mathrm{OHC}$, on both a personal and a professional level. They experience feelings of restlessness, loss of confidence, uncertainty, and lack of control over their personal life as well as their professional role. Such experiences were labelled as health professional moderators' challenges. 
On a personal level, all of the health professional moderators reported experiencing feelings of overload and high burden. Participation in the OHC often made them feel overwhelmed, leading to a lack of time, perceived loss of control, and feelings of difficulty managing their everyday life:
Yes, sometimes it was hard, um I had a full time job, a small child, I managed a helpline for women, that association and another association, and I was overloaded. And also, it was a time of a lot of questions and we hardly managed ... and sometimes there was a panic, it was a lot of everything and I couldn't manage. (Lucia, psychologist)

Beside the feelings of overload, several mentioned feelings of over-commitment to the OHC. They expressed feeling accountable for their work in the $\mathrm{OHC}$ and obligated to help the users. Sometimes, they felt that they had bound themselves beyond the capacity for realization. As Blanca (psychiatrist) explained:
...sometimes in the evening, when I'm already tired from everything and I still have some questions to answer, or I wake up in the middle of the night and I say to myself "good, I will use the insomnia for this." Weekends never really are um, it's always a good time to clean the inbox, so this might be a downside, a downside you reconcile with.

The majority of health professional moderators mentioned that the role of moderator in the OHC is emotionally burdensome because they often felt affected by tough cases, especially when they were confronted with users' serious and complicated situations:

\footnotetext{
For example, sometimes in just one day there are so many questions and I go quickly through and I read them and I say to myself "this one I can do, but this one I really don't want to. This one is first in line and I hope that someone else will do it, because I really can't, I don't have time, I don't have energy, I don't have the patience." You know, some things really get to you. (Jane, psychologist)
} 
The health professional moderators also experienced challenges on a professional level. They expressed feelings of uncertainty about the co-responsibility approach in the professionalpatient relationships emerging in the OHC. Many of the health professional moderators mentioned concerns about transferring health-related responsibility and decision making to users. They saw the $\mathrm{OHC}$ as a domain that intensively advocates and promotes the 'self-care' approach in professional-patient relationships. In the $\mathrm{OHC}$, this means that users are often left to make their own decisions about health management, and the health professional moderators usually do not receive any feedback about their decisions and further health-related actions. Such an approach can promote an active interest in users' health, but it also burdens the health professional moderators with feelings of doubt:

There are doctors who wouldn't agree with this, because hmm how can I explain, patients do not usually have enough education to responsibly decide and I think that there is sometimes too much responsibility put on their shoulders in comparison to the level of knowledge that they have, and I think this is problematic. (Blanca, psychiatrist)

Some health professional moderators mentioned feelings of public exposure. They explained that they felt like their work was being supervised and openly viewed by people, their colleagues, or other professionals. They thus felt more vulnerable to criticism: 'Sometimes, I felt that the questions were asked by a doctor, sometimes you um, for each response that I write I know that all my colleagues will read it...' (Sabina, medical geneticist). The feelings of exposure made them more cautious of their work as health professional moderators, as Sabina (medical geneticist) further explained:

Here you can't afford any lightness in answers, these answers remain online forever, so you need to put real effort into each and every reply and, um, then you have to be aware or I'm aware that my answers will be read by many doctors.

\section{Discussion}


The primary aim of this study was to explore the views of health professionals as moderators on their participation in OHCs. Through the data-driven thematic analysis, we found that the perspectives of health professional moderators shed new light on the impact of OHCs on OHC users, health professionals, and interactions between them. More precisely, the analysis revealed that health professional moderators experience several benefits and challenges when managing interactions with the OHC's users and addressing their needs, as well as personal and professional benefits and challenges. All these affect the way they perceive their interaction with $\mathrm{OHC}$ patients and other users, the role of health professionals in the $\mathrm{OHC}$, and the function of the $\mathrm{OHC}$ in the general health care system. Conceptually, these phenomena can be linked to ideas of empowerment processes and empowerment outcomes, as proposed by empowerment theory (Zimmerman, 1995).

For the majority of interviewed health professional moderators, their participation in the $\mathrm{OHC}$ was seen as beneficial to the OHC's users and their health-related needs. Health professional moderators see themselves as agents of empowerment processes and outcomes (Zimmerman, 1995), since they create opportunities for the OHC's users to broaden knowledge, develop skills, expand their social support, and gain other important resources necessary when dealing with health-related issues. Feelings of control, self-efficacy, competence, and critical selfawareness of the events and situations that determine individuals' lives are often understood as components of psychological empowerment (Laverack, 2006; Zimmerman, 1995). The state of psychological empowerment - often referred to as patient empowerment in health care literature (Anderson \& Funnell, 2010; Menon, 2002) - leads patients to a greater level of independency, autonomy, self-management, and effectiveness in health-related decision making (Schulz \& Nakamoto, 2013). The perceived benefits for OHC patients and other users may thus be understood as empowering processes, in which health professional moderators are catalysts of users' empowerment as they 'bestow power upon' (Lincoln, Travers, Ackers, \& 
Wilkinson, 2002) ordinary OHC users. Health professional moderators enable OHC users to actively confront their health issues, develop appropriate competences, and gain health-related knowledge and greater control over their own health situations or health situations of those they care for (Mo \& Coulson, 2014; van Uden-Kraan et al., 2008). Indeed, Barak, BonielNissim, and Suler (2008) and van Uden-Kraan et al. (2009) considered OHCs to foster the empowerment of users and thus improve psychological factors when dealing with healthrelated distress. Previous studies have shown the importance of OHCs for the psychological empowerment of users, however our research adds to the understanding of the processes and outcomes of empowerment, since it considers also the role of health professional moderators in OHCs.

Health professional moderators can be understood as facilitators of OHC users' empowering processes via practices such as sharing up-to-date health-related knowledge, raising awareness, addressing misconceptions about health conditions, enabling and supervising the exchange of patient expertise, and supporting the development of cooperative relationships between health professionals and $\mathrm{OHC}$ patients and other users. Thus, health professional moderators contribute to improving $\mathrm{OHC}$ users' health literacy and affect their ability to actively manage their health or health of those they care for, gain sufficient information, actively engage with their assigned personal doctors, and better navigate the health care system. These abilities and competences have often been emphasized as key determinants of individuals' health behaviour, use of health care services, and even public health care costs (Jin, Yan, Li, \& Li, 2016; Nutbeam, 2008).

Health professional moderators' activities in OHCs may be understood also as one important set of factors that facilitate $\mathrm{OHC}$ users in reaching empowerment outcomes, since they perceive themselves as someone who informs and educates users, includes them in a wider support system, expands their access to health care, and builds on trust in professional-patient 
relationships. These findings are in concordance with previous research investigating patients' participation in OHCs (Hartzler \& Pratt, 2011; Huh et al., 2013) and suggest that patients who are provided with online clinical expertise reported various empowerment outcomes, such as enhanced ability to manage health conditions, improved acceptance of the disease, increased self-efficacy, and improved quality of interactions with their doctors.

The presence of health professional moderators in OHCs is clearly beneficial, although their activities do not bring users solely advantages. Health professional moderators' activities that facilitate patients and other users' empowerment outcomes also involve specific set of responsibilities, duties and limitations (Kamin, 2006). As the health professional moderators reported, these limitations were in OHC moderator-user interactions often perceived as difficulties in providing users with adequate counselling and online medical service: experiencing issues of ethics and data protection, dealing with users' lack of essential information, adapting medical terminology, providing informational and emotional support, dealing with the problem of inventiveness, and the presence of professional conflicts. Such challenges were similarly suggested in previous research, e.g., Huh and Pratt (2014), who discovered that a lack of a general impression of OHC users' appearance, building appropriate connections and trust with them, and liability issues are common challenges when providing appropriate online clinical help. This may be due to the absence of non-verbal cues, which play an important role in medical consultations by providing health professionals with clues to patients' underlying concerns and emotions and even help to build professional-patient relationships (Silverman \& Kinnersley, 2010). From this perspective, challenges in addressing users' needs can be considered as a critical point that needs to be resolved in OHCs and other Internet-based applications to ensure the positive effects of health-related Internet use for patients and their relationships with health professionals. 
The analysis of the interviews revealed also that empowerment processes affect $\mathrm{OHC}$ users as well as health professional moderators. Participation in the $\mathrm{OHC}$ brought the health professional moderators increased feelings of self-fulfilment, self-worth, satisfaction, and sense of community. Furthermore, the health professional moderators also reported on improving their professional recognition in the wider professional community. In the context of empowerment theory, it can be stated that health professional moderators gained "power within' that increases an individual's personal and professional self-esteem and awareness of her/his capacity to motivate possible social practices (Dowding, 2011). The professional empowerment of health professional moderators can also be understood as empowerment in the workplace (Spreitzer, 1995), which is an intrinsic task motivation that manifests in increased personal meaning, competence, self-determination, and impact in relation to a specific 'work' environment. These findings are in concordance with previous studies examining online communities (Minkler, Thompson, Bell, \& Rose, 2001; Wang \& Fesenmaier, 2003) and suggest that a high level of online community involvement not only brings members meaning, but also enhances their feelings of membership, sense of belonging, and motivation. Moreover, online community involvement 'may have important by-products', which include beliefs in individual and community capacity, a higher level of trust, and greater interest in community needs (Minkler et al., 2001, p. 784). Involvement in community activities, such as moderation roles, exchange of support, and co-creation of community values and norms all enhance feelings of personal relevance (for the community), which are often reflected in an increased level of psychological empowerment (Minkler et al., 2001; Wang \& Fesenmaier, 2003).

The analysis of the reported challenges suggests that participation in the $\mathrm{OHC}$ was to some extent also disempowering for the health professional moderators. On a personal level, the health professional moderators reported weariness, exhaustion, stress, and a high level of 
responsibility that they associated with the role of health professional moderator. On a professional level, they felt publicly exposed to critics from their professional colleagues, which they associated with feelings of vulnerability, and potentially a damaged reputation. Health professional moderators often experience online situations in the opposite way to users. Anonymity, invisibility, and the possibility to easily escape or dissociate from what happens online gives users a disinhibiting effect (Suler, 2004), which is considered to be one of the beneficial factors for users in online therapy and OHCs (Barak et al., 2008). In contrast, the visibility and unconcealed presence of health professional moderators in OHCs makes them more self-consciousness and cautious in their interactions with users, especially in cases with possible ethical and liability issues. Although health professional moderators experience feelings of exposure as challenging, they are aware that the disclosure of their identity gives their advice and replies credibility that is often missing in unmoderated OHCs.

One particularly important disempowering outcome identified by the health professional moderators pertains to the professional-patient relationship, namely doubt in the coresponsibility approach that might be advocated by the OHCs. The co-responsibility approach in interaction with $\mathrm{OHC}$ users might overly promote users' self-care in health management and the transfer of responsibility for health-related decision making to users. What seems to be particularly disempowering for health professional moderators is not so much losing their power in the decision-making process per se, but rather losing track of the totality of health related actions undertaken by the $\mathrm{OHC}$ user. The active involvement of $\mathrm{OHC}$ users in making health-related decision is perceived positively, however the health professional moderators acknowledge users' potential 'bad literacy’ (Schulz \& Nakamoto, 2013) that might lead them to poor decisions away from health professional moderators' eyes.

OHCs have often been discussed as a source of the possible erosion of the role of medical/health professionals (Ahmad, Hudak, Bercovitz, Hollenberg, \& Levison, 2006). 
Interestingly, as active health professionals embedded in the domain of $\mathrm{OHCs}$, the health professional moderators did not express doubts about the OHC's impact on the role of health professionals in the health care system, although they perceived uncertainties emerging from the functioning of the wider health care system. With the transformation of the traditional paternalistic relationship between health professionals (usually medical doctors) and patients, the health professional moderators' doubt might emerge from current tendencies toward more partnership-oriented relations with patients in ('offline') health care practices, in which health professionals often experience a power shift in the decision-making process. However, as other studies have suggested (Broom, 2005), health professional moderators' reflections show that health professionals have a tendency to actively shape and co-create how the Internet and OHCs complement their expert role in the professional-patient 'offline' relationship toward a potentially more open and consultative approach rather than the enforcement of the traditional medical hierarchy.

\subsection{Practical implications}

The findings of this study have several practical implications for managers, designers, and developers of OHCs, as well as for health care policy makers. The study can inform managers of OHCs how health professional moderation practices can be improved and managed so as to improve participation of health professionals as moderators in the $\mathrm{OHC}$ and provide positive health-related outcomes for its members. The benefits and challenges that we identified in our study could be used to address the barriers and facilitators of experts' participation in OHCs. They provide a baseline for reasoning on motivating more health professionals to participate in OHCs. Maintaining a base of health professional moderators who are actively involved in the $\mathrm{OHC}$ is a difficult task for online community managers, as it often demands a high level of resources, both human and financial. 
The study suggests the need for close cooperation between OHCs' management and health professional moderators in contemplating and implementing appropriate managerial solutions. Moreover, the identified benefits and challenges could serve as a starting point for developing guidelines for more effective participation in the $\mathrm{OHC}$. As it is not always possible to eliminate disempowering processes and outcomes from online practices, online community managers may prepare health professional moderators with appropriate training, implementation of support systems, or machine learning decision-making systems, based on the messages already produced by health professional moderators and users in a particular OHC. Further research on practical aspects of this topic should focus on experimenting with different roles of health professional moderators, but also on the optimization of design of OHCs to allow functionalities for more efficient question answering process and group moderation.

\subsection{Limitations of the study}

The major limitation of this study is a small sample size, which limits the ability to generalize the findings. Although the data allowed us to reach saturation, bigger sample, various national contexts, and their comparison would lead to more conclusive findings. Furthermore, a quantitative study on a larger sample of health professional moderators might be an appropriate method with which to validate the results of this qualitative study.

Second limitation of this study is that in the interviews, the health professional moderators were asked to reflect on their past and present experiences in the $\mathrm{OHC}$, which introduced a bias in that they likely reported on the experiences that were more prominent at the time of the interview. Third, whilst this study included a broad range of health-related topics covered by the health professional moderators (from cardiology to psychotherapy), there is still a relative bias towards health conditions. Although differences in health professional moderators' views covering different medical fields were not evident in the data, future works may seek to extend the type of health professional moderators participating in the study. 


\section{Conclusion}

The present study offers a novel insight into the experiences of health professional voluntarily participating as moderators in OHCs. The study showed that OHCs with health professional moderators provide opportunities to build interactions between professional and patient or other $\mathrm{OHC}$ users oriented toward building more cooperative relationships. In this process special attention should be focused on striking a balance between autonomous but responsible 'self-care' of OHC users and the scientifically-based authoritative role of health professionals. Health professional moderators in OHCs are seen as representatives of the medical profession and so can potentially become advocates of consultative professional-patient relationships, as well as guides indicating how to improve OHCs and their role in the health care system. In this sense, $\mathrm{OHCs}$ can be seen as an experimental terrain where health professionals and patients or other $\mathrm{OHC}$ users are involved in a specific type of relationship that can be instructive, informative, transformative, and educative for both groups. This study thus brings an important finding that the potential of OHCs to empower patients partly depends on involvement of health professionals as moderators and their approaches in online medical consultations. Hence, future research should address the question of how to attract health professionals to participate as moderators in OHCs in a way that would be generally empowering also for them.

\section{Funding}

This work was supported by the Slovenian Research Agency (ARRS).

\section{References}

Ahmad, F., Hudak, P. L., Bercovitz, K., Hollenberg, E., \& Levinson, W. (2006). Are physicians ready for patients with Internet-based health information? Journal of Medical Internet Research, 8(3), e22. doi: 10.2196/jmir.8.3.e22

Anderson, R. M., \& Funnell, M. M. (2010). Patient empowerment: Myths and misconceptions. Patient Education and Counseling, 79(3), 277-282. doi: 10.1016/j.pec.2009.07.025 
Barak, A., Boniel-Nissim, M., \& Suler, J. (2008). Fostering empowerment in online support groups. Computers in Human Behavior, 24(5), 1867-1883. doi: 10.1016/j.chb.2008.02.004

Braun, V., \& Clarke, V. (2006). Using thematic analysis in psychology. Qualitative Research in Psychology, 3(2), 77-101. doi: 10.1191/1478088706qp063oa

Braun, V., \& Clarke, V. (2013). Successful Qualitative Research: A Practical Guide for Beginners. London: Sage.

Broom, A. (2005). Virtually he@1thy: The impact of internet use on disease experience and the doctor-patient relationship. Qualitative Health Research, 15(3), 325-345. doi: $10.1177 / 1049732304272916$

Coulson, N. S., \& Shaw, R. L. (2013). Nurturing health-related online support groups: Exploring the experiences of patient moderators. Computers in Human Behavior, 29(4), 1695-1701. doi: 10.1016/j.chb.2013.02.003

Dowding, K. (Ed.). (2011). Encyclopedia of Power. London: Sage.

Hartzler, A., \& Pratt, W. (2011). Managing the personal side of health: How patient expertise differs from the expertise of clinicians. Journal of Medical Internet Research, 13(3), e62. doi: 10.2196/jmir.1728

Huh, J. (2015). Clinical questions in online health communities: The case of "see your doctor" threads. In Proceedings of the 18th ACM Conference on Computer Supported Cooperative Work \& Social Computing (pp. 1488-1499). New York, NY: ACM.

Huh, J., Marmor, R., \& Jiang, X. (2016). Lessons Learned for Online Health Community Moderator Roles: A Mixed-Methods Study of Moderators Resigning From WebMD Communities. Journal of Medical Internet Research, 18(9). 
Huh, J., McDonald, D. W., Hartzler, A., \& Pratt, W. (2013). Patient moderator interaction in online health communities. In AMIA Annual Symposium Proceedings (pp. 627-636). Bethesda, MD: AMIA.

Huh, J., \& Pratt, W. (2014). Weaving clinical expertise in online health communities. In Proceedings of the SIGCHI Conference on Human Factors in Computing Systems (pp. 1355-1364). New York, NY: ACM.

Hwang, K. O., Ottenbacher, A. J., Green, A. P., Cannon-Diehl, M. R., Richardson, O., Bernstam, E. V., \& Thomas, E. J. (2010). Social support in an Internet weight loss community. International journal of medical informatics, 79(1), 5-13. doi: http://dx.doi.org/10.1016/j.ijmedinf.2009.10.003

Jin, J., Yan, X., Li, Y., \& Li, Y. (2016). How users adopt healthcare information: An empirical study of an online Q\&A community. International journal of medical informatics, 86, 91-103. doi: http://dx.doi.org.nukweb.nuk.uni-lj.si/10.1016/j.ijmedinf.2015.11.002

Johnston, A. C., Worrell, J. L., Di Gangi, P. M., \& Wasko, M. (2013). Online health communities: An assessment of the influence of participation on patient empowerment outcomes. Information Technology \& People, 26(2), 216-235. doi: http://dx.doi.org/10.1108/ITP-02-2013-0040

Jones, R. B., \& Ashurst, E. J. (2013). Online anonymous discussion between service users and health professionals to ascertain stakeholder concerns in using e-health services in mental health. Health Informatics Journal, 19(4), 281-299.

Kamin, T. (2006). Zdravje na barikadah: dileme promocije zdravja [Health on the barricades: Dilemmas of health promotion]. Ljubljana: FDV.

Laverack, G. (2006). Improving health outcomes through community empowerment: A review of the literature. Journal of Health, Population and Nutrition, 24, 113-120. 
Lincoln, N. D., Travers, C., Ackers, P., \& Wilkinson, A. (2002). The meaning of empowerment: The interdisciplinary etymology of a new management concept. International Journal of Management Reviews, 4(3), 271-290.

Menon, S. T. (2002). Toward a model of psychological health empowerment: Implications for health care in multicultural communities. Nurse Education Today, 22(1), 28-39. doi: $10.1054 /$ nedt.2001.0721

Minkler, M., Thompson, M., Bell, J., \& Rose, K. (2001). Contributions of community involvement to organizational-level empowerment: The federal healthy start experience. Health Education \& Behavior, 28(6), 783-807.

Mo, P. K. H., \& Coulson, N. S. (2010). Empowering processes in online support groups among people living with HIV/AIDS: A comparative analysis of 'lurkers' and 'posters'. Computers in Human Behavior, 26(5), 1183-1193. doi: 10.1016/j.chb.2010.03.028

Mo, P. K., \& Coulson, N. S. (2012). Developing a model for online support group use, empowering processes and psychosocial outcomes for individuals living with HIV/AIDS. Psychology \& Health, 27(4), 445-459. doi: $10.1080 / 08870446.2011 .592981$

Mo, P. K. H., \& Coulson, N. S. (2014). Are online support groups always beneficial? A qualitative exploration of the empowering and disempowering processes of participation within HIV/AIDS related online support groups. International Journal of Nursing Studies, 51(7), 983-993. doi: 10.1016/j.ijnurstu.2013.11.006

Nutbeam, D. (2008). The evolving concept of health literacy. Social Science \& Medicine, 67(12), 2072-2078. doi: 10.1016/j.socscimed.2008.09.050

Petrovčič, A., \& Petrič, G. (2014a). Differences in intrapersonal and interactional empowerment between lurkers and posters in health-related online support 
communities. Computers in Human Behavior, 34, 39-48. doi: 10.1016/j.chb.2014.01.008

Petrovčič, A., \& Petrič, G. (2014b). Dejavniki psihološkega kolektivnega opolnomočenja aktivnih uporabnikov spletne zdravstvene skupnosti Med.Over.Net [Factors of collective psychological empowerment of active users in the online health community Med.Over.Net]. Zdravstveno varstvo, 53(2), 133-148. doi: 10.2478/sjph-2014-0014

Schulz, P. J., \& Nakamoto, K. (2013). Patient behavior and the benefits of artificial intelligence: The perils of "dangerous" literacy and illusory patient empowerment. Patient Education and Counseling, 92(2), 223-228. doi: 10.1016/j.pec.2013.05.002

Silverman, J., \& Kinnersley, P. (2010). Doctors' non-verbal behaviour in consultations: Look at the patient before you look at the computer. British Journal of General Practice, 60(571), 76-78. doi: 10.3399/bjgp10X482293

Spreitzer, G. M. (1995). Psychological empowerment in the workplace: Dimensions, measurement, and validation. Academy of Management Journal, 38(5), 1442-1465.

Statistical Office of the Republic of Slovenia. (2015). Usage of Information-Communication Technologies (ICTs) in Households and by Individuals, Slovenia, 2015. Retrieved from www.stat.si.

Strauss, A., \& Corbin, J. (1998). Basics of qualitative research: Techniques and procedures for developing grounded theory. Sage Publications, Inc.

Suler, J. (2004). The online disinhibition effect. Cyberpsychology \& Behavior, 7(3), 321-326. doi: $10.1089 / 1094931041291295$

University of Ljubljana (2014). Code of ethics for researchers of University of Ljubljana. Retrieved from http://www.uni-lj.si/mma/Eti\%C4\%8Dni\%20kodeks\%20za\% 20raziskovalce\%20UL/2014 1211104120/ 
van Uden-Kraan, C. F., Drossaert, C. H. C., Taal, E., Seydel, E. R., \& van de Laar, M. A. F. J. (2008). Self-reported differences in empowerment between lurkers and posters in online patient support groups. Journal of Medical Internet Research, 10(2), e18. doi: 10.2196/jmir.992

van Uden-Kraan, C. F., Drossaert, C. H. C., Taal, E., Seydel, E. R., \& van de Laar, M. A. F. J. (2009). Participation in online patient support groups endorses patients' empowerment. Patient Education and Counseling, 74(1), 61-69. doi: 10.1016/j.pec.2008.07.044

van Uden-Kraan, C. F., Drossaert, C. H., Taal, E., Seydel, E. R., \& van de Laar, M. A. F. J. (2010). Patient-initiated online support groups: Motives for initiation, extent of success and success factors. Journal of Telemedicine and Telecare, 16(1), 30-34. doi: $10.1258 /$ jtt.2009.001009

Wang, Y., \& Fesenmaier, D. R. (2003). Assessing motivation of contribution in online communities: An empirical investigation of an online travel community. Electronic Markets, 13(1), 33-46. doi: 10.1080/1019678032000052934

Wentzer, H. S., \& Bygholm, A. (2013). Narratives of empowerment and compliance: Studies of communication in online patient support groups. International Journal of Medical Informatics, 82(12), e386-e394. doi: 10.1016/j.ijmedinf.2013.01.008

Young, C. (2013). Community management that works: How to build and sustain a thriving online health community. Journal of Medical Internet Research, 15(6), e119. doi: 10.2196/jmir.2501

Zimmerman, M. (1995). Psychological empowerment: Issues and illustrations. American Journal of Community Psychology, 23(5), 581-599.

Zhao, J., Ha, S., \& Widdows, R. (2013). Building trusting relationships in online health communities. Cyberpsychology, Behavior \& Social Networking, 16(9), 650-657. doi: 10.1089/cyber.2012.0348 